\title{
TẠO LẬP ĐÁM MÂY ĐIỂM 3D CỦA VẬT THỂ ĐộC LẬP BẦNG MÁY QUÉT LASER ĐONN TIA HOKUYO UTM LX30
}

\author{
PHAN TH! ANH THU \\ Trường Đại Học Bách Khoa - ĐHQG TP. HCM
}

\section{Tóm tắt:}

Hiện nay, công nghệ quét laser được xem nhu một công cu hũu dụng nhằm thu dũ liệu trong thời gian ngắn. Phuoong pháp đo gián tiếp này có thể thu thập dũ liệu đám mây điểm dày đặc mô tả vẻ ngoài mà không làm tổn hại vật thể. Nhằm giảm chi phi thiết bị, máy quét laser đơn tia $2 D$ Hokuyo UTM 30LX được sử dụng trong nghiên cứu này để tạo lập đám mây điểm $3 D$ cho vật thể được chon là một khối đá với hình dạng phức tạp. Máy quét được gắn trên một đường ray cố định trên khung nhôm. Tốc độ di chuyển của máy được điều khiển bởi mô to điện. Thiết bị được thiết lập để di chuyển theo hương thẳng đứng với tốc độ ổn định không đổi và được đặt ở nhiều vị trí khác nhau nhằm thu đủ dũ liệu bao phủ quanh đối tuợng. Một chuoong trình được phát triển trên ngôn ngũ $R$ để tạo ra đám mây điểm tù̀ dũ liệu được thu thập. Dựa trên nhũng mốc phản quang được đánh dấu, 6 đám mây điểm được tạo thành tù dũ liệu quét của 6 trạm, và được ghép lại với nhau để tạo mô hình $3 D$ đầy đủ của khối đá. Nhìn chung, một vài phần của khối đá bị che khuất bởi nhũng vật thể khác. Tuy nhiên, đám mây điểm $3 D$ thu được có mật độ dày đặc (3 triệu điểm), tưong đồng về hình dạng và kích thước so với vật thể thực.

Tù khóa: Point cloud, mô hình 3D, Hokuyo UTM 30LX, quét laser

\section{1. Đặt vấn đề}

Các công trình kiến trúc là thành quả sáng tạo to lớn của con người. Nhiều công trình kiến trúc cổ được xây dựng từ lâu đã xuống cấp, hư hỏng, không còn nguyên vẹn do nhiều yếu tố khách quan và chủ quan. Cùng với sự phát triển của khoa học công nghệ, việc số hóa, lưu trữ các công trình xây dựng là điều cần thiết nhằm quản lý, đánh giá hiện trạng để có kế hoạch duy tu vào bảo dưỡng cho phù hợp. Vì vậy, việc quản lý thông tin công trình phục vụ công tác trùng tu, sửa chữa, giữ lại nét đặc trưng của từng công trình là hết sức cần thiết và có ý nghĩa.

Để xác định hình dạng và kích thước của công trình, phương pháp đo trực tiếp bằng máy toàn đạc cho độ chính xác cao. Tuy nhiên, các cạnh đo và các điểm đo rời rạc không thể hiện chi tiết hình ảnh tổng thể của đối tượng cũng như mối tương quan không gian giữa chúng. Ngoài ra, số lượng điểm đo ít nên không dễ để hình dung cụ thể hiện trạng của công trình. Một số đối tượng có hình dạng phức tạp hoặc nằm ở những vị trí không thể tiếp cận sẽ ảnh hưởng đáng kể đến tính hiệu quả của những phương pháp đo đạc trực tiếp đã và đang được sử dụng.

Thực tế, nhu cầu tái tạo hiện trạng bề mặt đối tượng liên quan đến nhiều chuyên ngành nhằm nâng cao chất lượng cuộc sống, chẳng hạn như quản lý xây dựng, theo dõi hậu quả của thảm họa thiên nhiên, điều tra hiện trường vụ án và khôi phục các vật thể hoặc công trình kiến trúc cổ có độ phức tạp cao. Nhiều nghiên cứu đã được thực hiện với nhiều mục đích như điều tra bể chứa nước Byzantine ở Istanbul (Temizer và cộng sự, 2013) hay mục đích quản lý dữ liệu BIM (Building Information Modeling) (Mill và cộng

Ngày nhận bài: 3/9/2021, ngày chuyển phản biện: 5/9/2021, ngày chấp nhận phản biện: 10/9/2021, ngày chấp nhận đăng: 15/9/021 
sự, 2014). Cùng với sự phát triển của BIM, việc tạo ra hình ảnh $3 \mathrm{D}$ của cấu trúc hoặc vật thể trở thành nhiệm vụ được ưu tiên. Mô hình ba chiều (3D) của một đối tượng hỗ trợ các kỹ sư kiểm soát dự án hiệu quả hơn không chỉ trong giai đoạn thiết kế hoặc giai đoạn xây dựng mà còn trong giai đoạn bảo trì. Đồ họa trực quan 3D cho phép các kỹ sư đánh giá tình trạng của cấu trúc thông qua công tác nội nghiệp giúp giảm thiểu đáng kể khối lượng công việc thực hiện tại hiện trường. Ngoài ra, mô hình $3 \mathrm{D}$ còn hỗ trợ cho công tác đánh giá trực quan sự hài hòa của cấu kiện mới được thiết kế bổ sung cho các công trình đã tồn tại trước đó.

Có nhiều phương pháp tái tạo lại mô hình 3D của vật thể. Đối với các công trình xây dựng mới, mô hình 3D có thể được dựng lại từ bản vẽ thiết kế bằng phần mềm cụ thể. Tuy nhiên, đối với nhiều công trình xây dựng hiện có các bản vẽ thiết kế không còn được lưu trữ. Hiện nay, quét laser 3D là kỹ thuật có thể thu thập hàng triệu điểm dữ liệu trong vài phút; do đó, mô hình $3 \mathrm{D}$ của các tòa nhà hoặc vật thể có thể được tạo ra một cách dễ dàng và nhanh chóng (Chen và cộng sự, 2001; Sohn và cộng sự , 2005, Zhang và cộng sự, 2016). Quét laser là một kỹ thuật tiên tiến và được ứng dụng trong nhiều ngành công nghiệp, không chỉ trong lĩnh vực xây dựng. Một trong những ứng dụng thực tế nhất của phương pháp này được công nhận trong việc xây dựng lại Nhà thờ Đức Bà ở Pháp sau khi nó bị cháy vào năm 2019. Bằng cách sử dụng mô hình $3 \mathrm{D}$ được thu thập trước đó, các kỹ sư và nhà xây dựng có thể khôi phục lại cấu trúc ban đầu của nó một cách dễ dàng (Tallon và cộng sự, 2015).

Để tạo ra một mô hình trực quan hóa $3 \mathrm{D}$, các kỹ sư sử dụng máy quét laser Mặt đất (TLS) thu thập dữ liệu đám mây điểm bao phủ bề mặt của đối tượng mục tiêu. Máy quét laser 3D có nhiều ưu điểm là thu thập điểm mật độ cao, nhanh chóng và độ chính xác tốt. Tuy nhiên, giá thành thiết bị tăng dần cùng với yêu cầu cao về chất lượng của hình ảnh tạo ra. Tại Việt Nam, Bộ Tài nguyên và Môi trường đã ban hành Thông tư
17/2019/TT-BTNMT ngày 30 tháng 9 năm 2019 về "Quy định kỹ thuật thành lập mô hình số độ cao bằng công nghệ quét LiDAR mặt đất trên trạm cố định". Thực tế, một số đơn vị ở nước ta đã đi tiên phong trong việc tiếp cận và làm chủ kỹ thuật này nhưng vẫn gặp những khó khăn riêng. Rào cản này xuất phát từ việc giá thành thiết bị và phần mềm đi kèm còn tương đối cao so với mặt bằng thu nhập chung tại Việt Nam. Ngoài ra, công tác xử lý dữ liệu yêu cầu kỹ thuật viên có trình độ chuyên môn cao. Vì vậy, việc sử dụng máy quét laser chuyên dụng cho các dự án nhỏ là không kinh tế. Trong nghiên cứu này, một máy quét laser 2D giá rẻ, Hokuyo UTM 30LX, được sử dụng để tái tạo mô hình 3D của vật thể. Đối tượng của nghiên cứu này là một khối đá gồ ghề, kích thước trung bình với nhiều góc cạnh và chi tiết phức tạp.

\section{Thu thập dữ liệu}

\section{1. Đối tượng nghiên cúu}

Mục tiêu của nghiên cứu này là khối đá biểu tượng khoa Địa chất Dầu khí nằm trong khuôn viên Trường Đại học Bách Khoa - ĐHQG TP.HCM. Khối đá này có hình dạng rất phức tạp gồm nhiều gờ, rãnh và hốc nhỏ. Đối tượng nghiên cứu này có kích thước không quá lớn (Hình 1). Tuy nhiên, rất khó để xác định được chính xác hình dạng của khối đá bằng cách sử dụng phương pháp đo trực tiếp truyền thống. $\mathrm{Cụ}$ thể, mặt trước của khối đá hơi cong với biểu tượng logo trường và phần chân bị lõm sâu. Bên phải của khối đá bị khoét sâu tạo thành một hốc lớn. Mặt trái có dạng đường cong trơn. Phía sau khối đá tương đối phẳng. Các phần hơi nhô ra ở mặt trước và các phần khoét sâu tạo thành một bề mặt tổng thể phức tạp không thể đo đạc trực tiếp một cách chính xác.

\subsection{Mô tả hệ thống}

Để phát triển hệ thống, máy quét laser đơn tia Hokuyo UTM 30LX được chọn (Hình 2). Đây là một thiết bị nhỏ và trọng lượng nhẹ $(370 \mathrm{~g})$ với bước sóng $905 \mathrm{~nm}$, độ phân giải góc $0,25^{\circ}$ và trường quan sát tối đa $270^{\circ}$ (Bảng 1). Thiết bị được gắn vào một khung đặc biệt làm bằng nhôm 


\section{Nghiên cúu - Úng dung}

có đường ray điều hướng và một động cơ có thể thống được cung cấp năng lượng bởi một pin sạc điều chỉnh tốc độ (Hình 2). Máy quét laser có thể $12 \mathrm{~V}$ giúp duy trì thời gian vận hành liên tục đến di chuyển dọc theo ray trượt dưới sức mạnh của 2 giờ. Vị trí của máy quét có thể được điều chỉnh động cơ để ghi lại hình ảnh của bề mặt đối tượng bằng cách thay đổi vị trí tấm nhôm đỡ và cố định với tốc độ quét $25 \mathrm{msec} / 1$ ần quét. Toàn bộ hệ bằng các bu lông.

Bảng 1: Thông tin chi tiết của máy quét laser HOKUYO UTM 30LX

\begin{tabular}{|l|l|}
\hline Nguồn & $12 \mathrm{VDC} \pm 10 \%$ \\
\hline Bước sóng & $\lambda=905 \mathrm{~nm}$ \\
\hline Tầm quét & 0.1 đến $30 \mathrm{~m}$ \\
\hline Thị trường quét & $270^{\circ}$ \\
\hline Độ chính xác & $\begin{array}{l}\text { Tầm quét } 0.1 \text { đến } 10 \mathrm{~m}: \pm 30 \mathrm{~mm}, \\
\text { Tầm quét } 10 \text { đến } 30 \mathrm{~m}: \pm 50 \mathrm{~mm}\end{array}$ \\
\hline Độ phân giải góc quét & $0.25^{\circ}$ \\
\hline Tần suất & $25 \mathrm{msec} / \mathrm{scan}$ \\
\hline Khối lượng & $370 \mathrm{~g}($ Bao gồm dây nối) \\
\hline
\end{tabular}

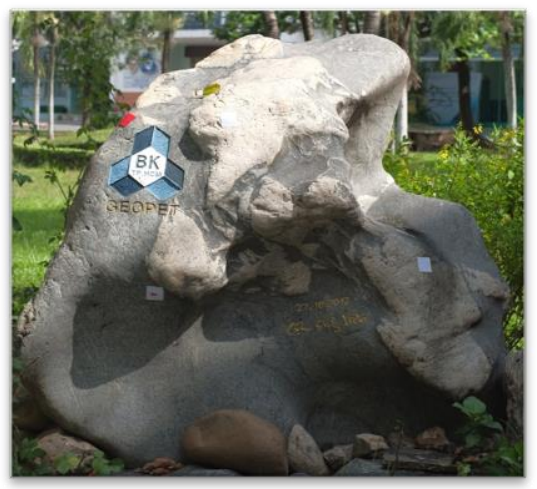

Hình 1: Khối đá biểu tuợng Khoa Địa chất dầu khí với nhiều góc cạnh tại khuôn viên Truờng Đại học Bách Khoa - ĐHQG TP. HCM. Các miếng dán phản quang được đánh dấu trên khối đá để kiểm tra so bộ dũ liệu trong quá trình thu nhận
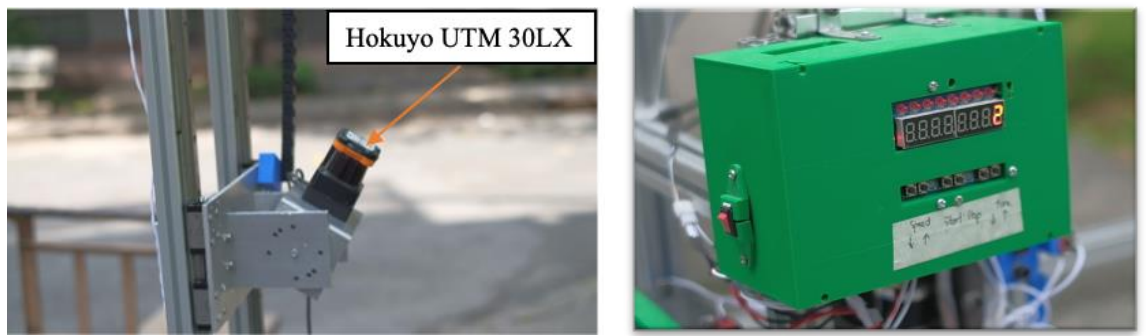

Hình 2: Mô tả hệ thống. (a) Máy quét laser đơn tia Hokuyo UTM 30LX được gắn trên khung nhôm và có thể di chuyển dọc theo đương ray và $(b)$ bộ điều khiển tốc độ di chuyển

a)

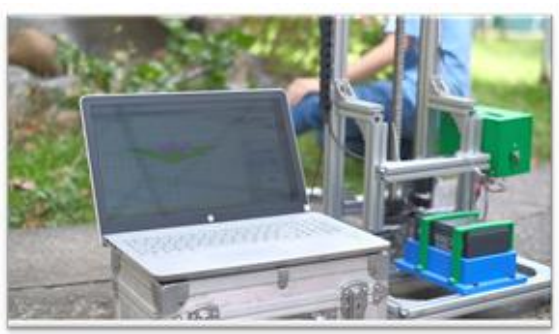

b)

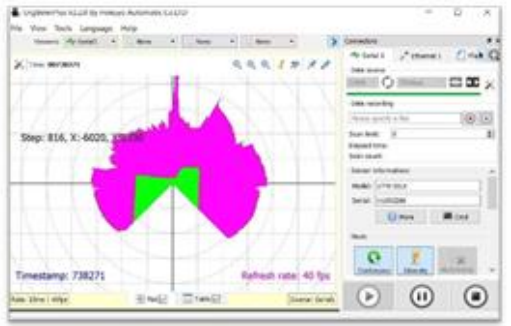




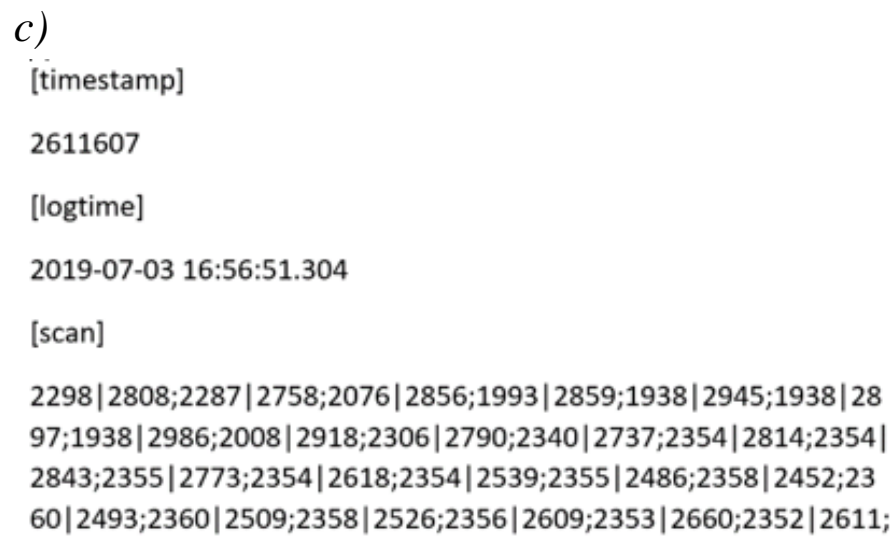

Hình 3: Thu thập dũ liệu tại hiện truờng. (a) Dũ liệu được thu thập thông qua phần mềm Urg Benri Plus chạy trên máy tính cá nhân tại khu vục nghiên cúu, (b) hình ảnh cuờng độ (màu xanh lá) và khoảng cách quét (màu hồng) được thể hiện trên chuoong trình, và (c) một phần dũ liệu của tiẹp tin *ubh

\subsection{Thu thập dĩ liệu}

Để tiến hành thu thập dữ liệu bề mặt của khối đá mục tiêu, cây cối hoặc chướng ngại vật xung quanh đối tượng được dọn dẹp để giúp tia laser có thể tiếp cận đối tượng và nâng cao độ chính xác của quá trình thu dữ liệu. Do đối tượng có hình dạng phức tạp và máy quét được sử dụng là máy đơn tia, bước sóng đơn nên không thể thu được hình ảnh trực quan đầy đủ của khối đá trong một lần quét. Do đó, cần bố trí nhiều trạm quét để thu được hình ảnh tổng thể của đối tượng. Hình ảnh của đối tượng được ghi nhận bởi máy quét ở nhiều vị trí khác nhau. Trên bề mặt đá, miếng dán phản quang $3 \mathrm{M}$ được sử dụng làm điểm đánh dấu (Hình 1 ). Các điểm đánh dấu này sẽ được sử dụng để kết hợp các đám mây điểm

a)

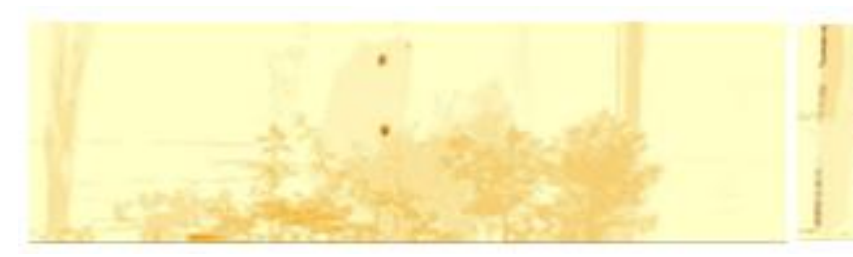

khác nhau trong nhiều trạm nhằm tạo thành mô hình đám mây đầy đủ hình dáng của đối tượng.

Trong nghiên cứu này, mặt phẳng quét được đặt vuông góc với đối tượng. Để bắt đầu quét, động cơ được thiết lập với tốc độ di chuyển không đổi bằng $20 \mathrm{~mm} / \mathrm{s}$, và máy quét laser được đặt để di chuyển theo hướng thẳng đứng với trường quan sát cài đặt là 180 độ (Hình 3). Máy quét được kết nối với máy tính xách tay và dữ liệu quan sát được thu thập bằng chương trình Urg Benri Plus (Hình 3b). Kết quả là dữ liệu thô có định dạng tệp *.ubh (Hình 3c). Đối với mỗi trạm, dữ liệu thô thu thập được đặt tên theo nguyên tắc "ddmmyy-ga-speed-angle" để giúp việc kiểm soát dữ liệu dễ dàng hơn. Kết quả có 6 tệp *.ubh được ghi nhận từ 6 vị trí quét khác nhau.

b)

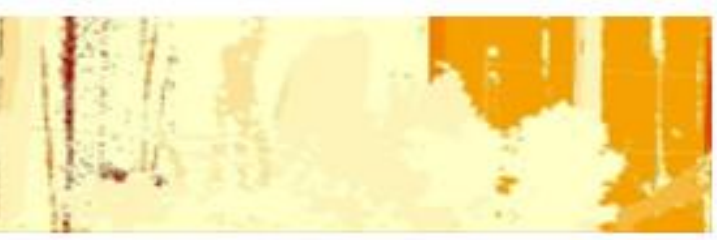

Hình 4: Kết quả trục quan hóa dũ liệu quét. (a) Hình ảnh cuờng độ và (b) khoảng cách quét tuoơng ưng của tùng điểm quét được thể hiện dựa trên thứ tụ điểm quét và dòng quét

\section{Phương pháp thực hiện}

Sau khi hoàn tất quá trình quét, tệp dữ liệu thô có định dạng *.ubh chứa dữ liệu hỗn hợp.
Mỗi dòng quét được đánh dấu bằng thời gian quét. Mỗi điểm quét trong dòng quét được tổ chức như là một block dữ liệu bao gồm giá trị 
cường độ phản xạ, và khoảng cách quét (Hình $3 c$ ). Do đó, dữ liệu thô rất phức tạp, quá trình xử lý dữ liệu thô được thực hiện bằng chương trình được phát triển trên ngôn ngữ $\mathrm{R}$. Thông tin cường độ và giá trị khoảng cách quét tương ứng với từng điểm được trích lọc từ dữ liệu thô và lưu trữ dưới định dạng text file. Mỗi dòng dữ liệu ghi nhận thông tin của một điểm quét bao gồm thời gian quét, thứ tự dòng quét, thứ tự điểm quét, cường độ phản xạ và khoảng cách quét. Giá trị cường độ phản xạ và khoảng cách được hiển thị trực quan dưới định dạng ảnh JPEG (Hình 4).

Để tạo đám mây điểm 3D từ dữ liệu được máy quét laser 2D thu thập, bước đầu tiên là chuyển đổi tọa độ cực của điểm quét trong mỗi dòng quét (khoảng cách $\mathrm{D}$, góc quét ngang $\theta$ ) sang hệ tọa độ máy quét cục bộ. Hệ tọa độ máy quét laser được giả định là hệ tọa độ 3D được lập theo nguyên tắc bàn tay phải với điểm gốc nằm tại gương phản xạ của thiết bị. Hệ tọa độ này được thiết lập dựa trên mặt phẳng quét và hướng chuyển động của thiết bị. Cụ thể, trục $\mathrm{X}$ song song với thanh trượt và chiều dương là chiều chuyển động của máy quét. Trục $Z$ thuộc mặt phẳng quét vuông góc với trục $X$, và chiều dương của nó hướng về đối tượng được khảo sát. Trực Y được xác định theo quy tắc bàn tay phải. Do đó, tọa độ của các điểm trong mỗi dòng quét được tính bằng công thức

$$
\begin{gathered}
x^{L S}=0 \\
y^{L S}=r \cdot \sin \theta \\
z^{L S}=r \cdot \cos \theta
\end{gathered}
$$

Trong đó:

$\left(x^{L S}, y^{L S}, z^{L S}\right)^{T}$ : Tọa độ của điểm trong hệ tọa độ máy quét

$\mathrm{r}$

$\theta$

Tọa độ $X$ của mỗi mặt phẳng quét được ước tính và điều chỉnh dựa trên giá trị vận tốc di chuyển được thiết lập. Bằng cách này, mỗi dòng quét sẽ được hiển thị dưới dạng một hàng ngang trên đám mây điểm. Đám mây điểm dày đặc được tổ chức dưới dạng các dòng quét không chồng chéo. Kết quả là, đám mây điểm $3 \mathrm{D}$ của mỗi trạm được tạo ra (công thức 2). Đám mây điểm này sẽ mô tả hình ảnh của đối tượng ở một góc nhìn cụ thể.

$$
\begin{gathered}
x=x^{L S}+v \cdot t \\
y=y^{L S} \\
z=z^{L S}
\end{gathered}
$$

Trong đó:

$(x, y, z)^{T}$ : Tọa độ $3 \mathrm{D}$ của điểm quét

$\left(x^{L S}, y^{L S}, z^{L S}\right)^{T}$ : Tọa độ của điểm trong hệ tọa độ máy quét

v: Vận tốc chuyển động $(\mathrm{m} / \mathrm{s})$

$\mathrm{t}$ : Thời gian di chuyển $(\mathrm{s})$

Trong quá trình thu thập dữ liệu, thị trường quét được thiết lập là $180^{\circ}$ nên dữ liệu chứa rất nhiều thông tin nhiễu không cần thiết. Do đó, các điểm quét nhiễu được loại bỏ trước khi tiến hành căn chỉnh và hợp nhất tất cả dữ liệu điểm đám mây. Để tiến hành ghép dữ liệu, bốn cặp điểm cùng tên (điểm trùng) ở hai đám mây điểm liền kề được lựa chọn. Mô hình chuyển đổi Affine được áp dụng. Các thông số chuyển đổi được tính toán và áp dụng để tính lại tọa độ của các điểm trong đám mây tham chiếu. Quá trình ghép dữ liệu được tiến hành tuần tự. Cụ thể, dữ liệu của trạm thứ nhất được ghép với trạm thứ hai; kết quả ghép trạm được sử dụng để nối với trạm tiếp theo. Quá trình này được lặp lại cho đến khi dữ liệu của trạm cuối cùng được đưa vào đám mây tổng thể.

\section{Kết quả}

Trong nghiên cứu này, máy quét laser Hokuyo UTM 30LX được sử dụng để thu nhận hình ảnh bề mặt của khối đá. Cụ thể, 6 trạm quét được thiết lập xung quanh mục tiêu và thu nhận được 6 tập tin thô định dạng *ubh. Chương trình xử lý dữ liệu thô được tạo lập bằng ngôn ngữ $\mathrm{R}$. Kết quả xử lý dữ liệu tạo được nhiều sản phẩm trung gian. Cụ thể, cường độ và khoảng cách cùng với góc quét được trích xuất và lưu trữ dưới dạng text file. Dũ liệu này được trực quan hóa thành dạng file ảnh để kiểm tra sơ bộ thông tin được ghi nhận. Hình ảnh cường độ thể hiện độ phản xạ của xung laser khi nó tiếp xúc bề mặt vật thể. Từ ảnh cường độ, có thể xác định sơ bộ hình 
dạng trực quan của đối tượng (Hình 4a). Giá trị phản xạ cao hay thấp phụ thuộc hoàn toàn vào bề mặt của vật liệu. Các miếng dáng phản quan có giá trị phản xạ rất cao. Do đó, trong quá trình thu dữ liệu có thể kiểm soát sơ bộ thông tin dựa trên biến động giá trị cường độ phản xạ hiển thị trên màn hình của chương trình thu nhận dữ liệu. Hình ảnh khoảng cách quét thể hiện giá trị khoảng cách tương ứng với từng vị trí quét. Tuy nhiên, sự khác biệt giữa phạm vi quan sát được là không lớn trong nghiên cứu này. Do đó, ảnh khoảng cách không hỗ trợ cho việc trực quan hóa hình dạng của đối tượng (Hình $4 \mathrm{~b}$ ). Sản phẩm cuối cùng là dữ liệu đám mây được lưu dưới định dạng file ghi nhận tọa độ 3D của từng điểm quét và cường độ phản xạ tương ứng.

Quá trình căn chỉnh và kết nối các đám mây điểm độc lập được thực hiện tuần tự cho từng cặp

a)

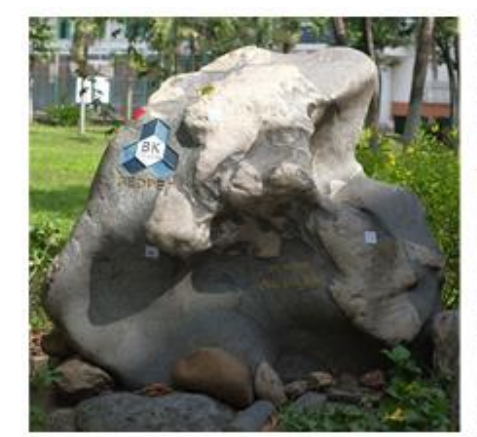

d)

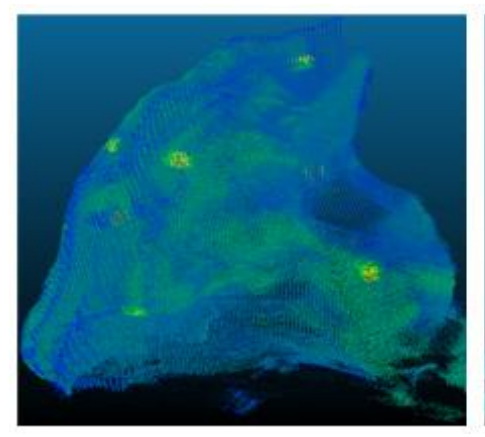

đám mây điểm liền kề bằng cách xác định 4 điểm liên kết (điểm trùng). Các thông số của mô hình chuyển đồi Affine chuyển đổi được tính từ bộ dữ liệu điểm trùng nhau và được áp dụng để tính lại tọa độ của đám mây điểm tham chiếu. Sau đó hai đám mây điểm được hợp nhất thành một đám mây tổng hợp. Kết quả, các đám mây điểm độc lập được hợp nhất với nhau và tạo nên hình ảnh đầy đủ của khối đá mục tiêu. Cụ thể, có hơn ba triệu điểm quét bao phủ bề mặt của khối đá. Khoảng cách giữa các điểm được ước tính là dưới $1 \mathrm{~cm}$. Do đó, từng chi tiết nhỏ của khối đá có thể được quan sát cụ thể trên đám mây thông qua màn hình máy tính. Ví dụ, logo của Trường Đại học Bách Khoa-ĐHQG TP.HCM nằm bên trong hình tròn màu đỏ, các hốc lớn, các góc cạnh, các bướu và vết lồi trên đá có thể được hình dung rõ ràng (Hình 5). b)

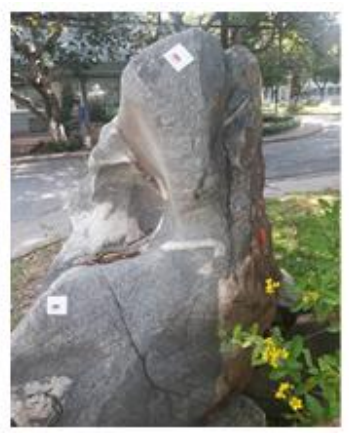

e)

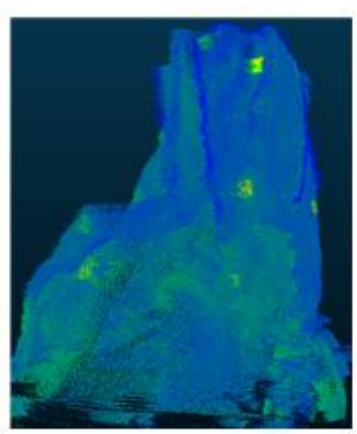

c)

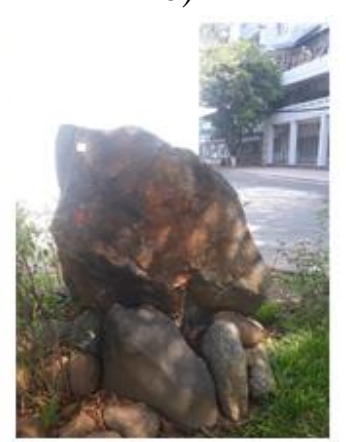

f)

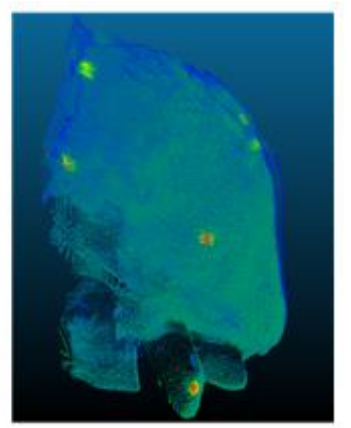

Hình 5: Kết quả tạo lập đám mây điểm của khối đá. (a-c) Hình ảnh thực và (d-f) hình ảnh đám mây của khối đá ở các góc nhìn khác nhau. Các chi tiết phức tạp cảu khối đá được hiện thị rõ ràng trên đám mây điểm

Trong quá trình thu thập dữ liệu, do ảnh hưởng của điều kiện ngoại cảnh nên một phần hình ảnh của khối đá bị che khuất và thiếu thông tin hiển thị. Cụ thể, một phần của tảng đá bị che bởi bụi cây, điều này ngăn cản tia laser tiếp xúc bề mặt khối đá. Tuy nhiên kết quả này ảnh hưởng không đáng kể đến chất lượng của đám mây được tạo lập. Với mật độ điểm dày đặc, bề mặt của khối đá được khôi phục hình dạng bằng cách xây dựng mạng lưới tam giác theo giải thuật Poisson Surface Reconstruction nhờ sự hỗ trợ của phần mềm mã nguồn mở Cloud Compare. 
Cuối cùng, mô hình 3D của khối đá được tạo lập (Hình 6). Từ mô hình này, chúng ta có thể đánh giá các đặc điểm của khối đá. Hơn nữa, kích thước thực tế của khối đá có thể được đo lường do mô hình được thành lập với tỷ lệ $1: 1$. Từ đó thể tích thực của khối đá được ước tính và sử dụng cho các phân tích tiếp theo.

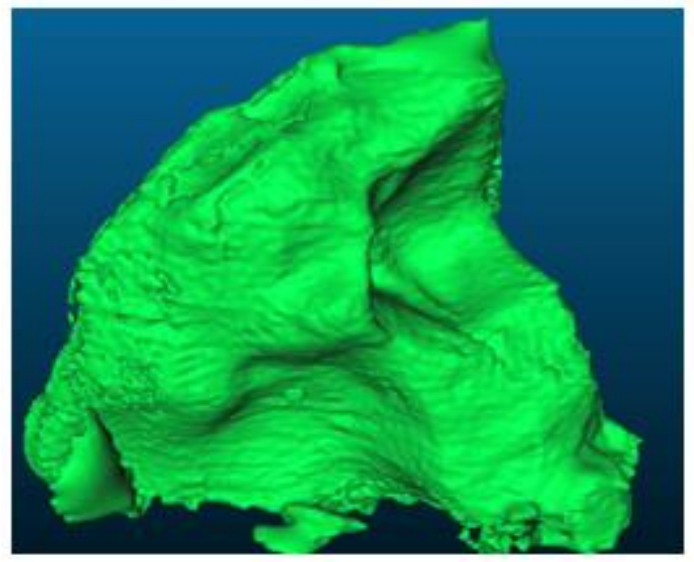

Hình 6: Mô hình bề mặt của khối đá được tạo lập dựa trên giải thuật Poisson Surface Reconstruction nhò sự hỗ trợ của phần mềm mã nguồn mở Cloud Compare

\section{Kết luận}

Trong nghiên cứu này, máy quét laser tia đơn Hokuyo UTM 30LX đã được sử dụng để thu thập dữ liệu về bề mặt của một khối đá có hình dạng đặc biệt. Có 6 đám mây điểm đã được tạo ra từ dữ liệu quan sát tại 6 trạm bằng cách sử dụng một tập lệnh được phát triển trên ngôn ngữ R. Cuối cùng, những đám mây điểm độc lập được hợp nhất với nhau để tạo thành hình ảnh đầy đủ của tảng đá nhờ áp dụng mô hình chuyển đổi Affine. Kết quả thu được đám mây điểm với mật độ dày đặc (hơn 3 triệu điểm). Khoảng cách giữa các điểm được ước tính dưới $1 \mathrm{~cm}$. Hình ảnh $3 \mathrm{D}$ của khối đá hiển thị từ đám mây điểm rất rõ ràng mặc dù có một số phần bị thiếu và nhiễu. Khối đá có nhiều góc cạnh và có thể dễ dàng quan sát từ đám mây điểm. Hình ảnh đám mây đủ rõ nét để minh họa các chi tiết khối đá so với hình ảnh gốc. Ngoài ra, theo thông số của máy quét laser, sai số khoảng cách quét trong mô hình xấp xỉ \pm 6 $\mathrm{mm}$ ở tầm quét $2 \mathrm{~m}$. Do đó chất lượng của mô hình đám mây điểm được đảm bảo. Với ưu điểm tạo lập được mô hình với tỷ lệ thực (1:1), kích thước của đối tượng có thể được xác định trực tiếp trên đám mây điểm.

Trong thử nghiệm này, số lượng các điểm phản quang được đánh dấu không đủ cho quá trình ghép dữ liệu vì hình dạng phức tạp của khối đá. Điều này dẫn đến khó khăn trong việc hợp nhất các đám mây điểm. Một số điểm đặc trưng của đối tượng được sử dụng để làm cơ sở liên kết các đám mây điểm với nhau. Hơn nữa, xung quanh tảng đá có nhiều cây cối và khối đá nhỏ khác che khuất đối tượng quét chính. Do đó, các dữ liệu không cần thiết cần được loại trừ trước khi hợp nhất dữ liệu.

Tóm lại, nghiên cứu đã tái tạo thành công mô hình $3 \mathrm{D}$ của tảng đá với khả năng hiển thị trực quan, chi tiết hình ảnh bề ngoài của đối tượng mặc dù có một số khu vực bị thiếu thông tin do các chướng ngại vật. Giai đoạn mô hình hóa mất rất nhiều thời gian do thiếu các điểm được đánh dấu và rất khó để tìm ra điểm chung để thực hiện gộp các đám mây. Trong tương lai, chúng tôi sẽ cố gắng cải thiện chất lượng của mô hình bằng cách bố trí đầy đủ các điểm đánh dấu, làm trống khu vực quanh đối tượng quét để giảm thiểu các điểm quét thừa, và thực hiện đo kiểm tra để đánh giá lại độ chính xác về mặt kích thước hình học của đối tượng được khảo sát. $\bigcirc$

\section{Lò̀i cảm ơn}

Tác giả gửi lời cảm ơn chân thành đến sinh viên Nguyễn Thái Khiêm và Nguyễn Đức Nhã 
đã nhiệt tình hỗ trợ trong quá trình thu thập dữ liệu.

\section{Tài liệu tham khảo}

[1]. Temizer, T., Nemli, G., Ekizce, E., Ekizce, A., Demir, S., Bayram, B., Askin, F. H., Cobanoglu, A. V., and Yilmaz, H. F.: 3d Documentation of A Historical Monument Using Terrestrial Laser Scanning Case Study: Byzantine Water Cistern, Istanbul, Int. Arch. Photogramm. Remote Sens. Spatial Inf. Sci., XL-5/W2, 623-628, https://doi.org/10.5194/isprsarchives-XL-5-W2623-2013, 2013.

[2]. Tarvo Mill, Aivars Alt, Roode Liias , Combined 3d Building Surveying TechniquesTerrestrial Laser Scanning (TLS) And Total Station Surveying For Bim Data Management Purposes, Journal of Civil Engineering and Management 19(sup1):S23-S32

[3]. Racheal Hartigan Shea, National Geographic - Historian uses laser to unlock mysteries of Gothic Cathedrals. https://www.nationalgeographic.com/adventure/ article/150622-andrew-tallon-notre-damecathedral-laser-scan-art-history-medievalgothic, truy cập vào tháng 4 năm 2021

[4]. The Specifications of Hokuyo UTM 30LX, (https://www.hokuyoaut.jp/search/single.php?serial=169)

[5]. Liang-Chien Chen, Huang-Hsiang Jan and Chen-Wei Huang. "Mensuration of concrete cracks using digital close-range photographs". Proceedings of the 22th Asian Conference on Remote Sensing, Singapore (2001): 1248-53.

[6]. Hong Gyoo Sohn, Yun Mook Lim, Kong Hyun Yun, Gi Hong Kim, "Monitoring crack changes in concrete structures", Computer-Aided Civil and Infrastructure Engineering, 20 (2005): 52-61.

[7]. Lei Zhang, Fan Yang, Yimin Daniel Zhang, Ying Julie Zhu. "Road crack detection using deep convolutional neural network". 2016 IEEE International Conference on Image Processing (ICIP) (2016)

https://doi.org/10.1109/ICIP.2016.7533052.○

\section{Summary}

\section{Generating 3D point cloud of a single object using a single beam laser scanner hokuyo UTM LX30}

\section{Phan Thi Anh Thu}

\section{Ho Chi Minh city university of technology-vnu}

Recently, LiDAR technology is considered as an useful tool for gathering data in a short time. Moreover, this indirect measurement can get a dense detail point cloud without damaging the object. For reducing the equipment cost, the low-cost single beam laser scanner Hokuyo UTM 30LX is used in this study for generating a 3D point cloud of a target object. The chosen target object in this study is a rock with non-uniform in shape. The scanner is mounted on a special aluminum frame with a railway and an adjustable speed motor. Many reflectance markers (GCPs) are stickled on the surface of the object for combining point clouds. For data collecting, the machine is set to travel in the vertical direction at a constant speed. To create the full 3D point cloud of the object, the system has been set up at different stations to obtain the whole image of the rock. After collecting data, a script is developed on $\mathrm{R}$ language to generate the point cloud from raw data. As a result, 6 point-clouds are generated. Basing on the marker positions, the generated point clouds are combined together using Cloud Compare application to make the full image of the rock. From this result, a mesh is generated for visualizing the 3D model of the rock. Some parts of the rock are missing because it is hidden by other objects. However, the 3D point cloud the object is generated with high density of points and its $3 \mathrm{D}$ model is visualized. $\mathrm{O}$

Key words: Point cloud, mô hình 3D, Hokuyo UTM 30LX, laser scanning 